\title{
Effective Dose Levels from Computed Tomography of the Head during Contrast Studies in Nigeria
}

\author{
Thomas Adejoh ${ }^{1}$, Nzotta Chukwuemeka Christian², Flavious Bobuin Nkubli ${ }^{3}$, \\ Joseph Zira Dlama ${ }^{4}$ \\ ${ }^{1}$ Radiology Department, Nnamdi Azikiwe University Teaching Hospital, Nnewi, Nigeria \\ ${ }^{2}$ Department of Radiography and Radiological Sciences, College of Health Sciences, Nnamdi Azikiwe University, \\ Nnewi Campus, Nnewi, Nigeria \\ ${ }^{3}$ Department of Medical Radiography, College of Medical Sciences, University of Maiduguri, Nigeria \\ ${ }^{4}$ Radiology Department, Abubakar Tafawa Balewa University Teaching Hospital, Bauchi, Nigeria \\ Email: adtoms@yahoo.com, nzottac@yahoo.com, activeflavour@yahoo.com, josephdlama@gmail.com
}

Received 4 July 2015; accepted 2 August 2015; published 5 August 2015

Copyright (C) 2015 by authors and Scientific Research Publishing Inc.

This work is licensed under the Creative Commons Attribution International License (CC BY).

http://creativecommons.org/licenses/by/4.0/

(c) (i) Open Access

\section{Abstract}

Background: Diagnostic reference levels for a number of common diagnostic radiological examinations against which individual centres could compare their performance have been recommended by relevant international agencies. Due to variations in different populations globally, local and national diagnostic reference levels are more reliable. To the best of our knowledge, no centre-specific study has been carried out and national surveys are not available. Objective: To establish a preliminary local and national diagnostic reference level in Nigeria. Methods: A prospective and cross-sectional study involving 30 conscious paediatrics and adult patients referred for head computed tomography scan. They were positioned supine and scanned according to the standard protocol for head computed tomography with manual mA selection. The total doselength products were recorded at the end of the pre-contrast and post-contrast sequences respectively. The pre-contrast dose was taken into cognizance in the determination of the post-contrast value. The effective dose was established by multiplying the dose-length product by 0.0023 $\mathrm{mSv} \cdot \mathrm{mGy}^{-1} \cdot \mathrm{cm}^{-1}$, a conversion coefficient for brain tissue adopted from the European Commission. Statistical Package for Social Sciences version 17.0 was used to analyze the data. Results: 30 paediatrics and adult patients of mixed gender participated in the study. Their ages ranged from 1 to 74 years with a mean age of $41.47 \pm 23.30$ years. The pre-contrast effective dose ranged from 1.93 $\mathrm{mSv}$ to $3.32 \mathrm{mSv}$ with mean of $2.56 \pm 0.51 \mathrm{mSv}$ and $75^{\text {th }}$ percentile of $3.11 \mathrm{mSv}$ while the postcontrast effective dose ranged from $4.06 \mathrm{mSv}$ to $6.97 \mathrm{mSv}$ with mean of $5.27 \pm 0.97 \mathrm{mSv}$ and $75^{\text {th }}$ percentile of $6.13 \mathrm{mSv}$. The mean effective dose from this work and two other isolated studies was *Corresponding author.

How to cite this paper: Adejoh, T., Christian, N.C., Nkubli, F.B. and Dlama, J.Z. (2015) Effective Dose Levels from Computed Tomography of the Head during Contrast Studies in Nigeria. Health, 7, 915-919. 
3.0 mSv. Conclusion: Although our quantified doses are below threshold limits for occupational exposures they are higher than the recommended level for the public. A further optimization of scanning protocols by the radiographers could lower the effective dose for patients undergoing contrast head computed tomography in our centre and in the country.

\section{Keywords}

Effective Dose, Diagnostic Reference Level, Radiographer, Computed Tomography, Head

\section{Introduction}

Computed tomography (CT) is associated with relatively high radiation doses, with a corresponding increased risk of carcinogenesis. Therefore, a strict adherence to dose justification, optimization and minimization which are the tenets of radiation protection must be ensured. At the core of this optimization is the establishment of diagnostic reference levels, DRLs [1].

Diagnostic reference levels were first mentioned by the International Commission on Radiological Protection, ICRP [2]. They are intended to be a reasonable indication of dose for average-size patients and to provide guidance on what is achievable with current good practice rather than optimum performance [3]. They allow the identification of abnormally high dose levels by setting an upper threshold. Thus, an awareness of typical dose levels allows CT users to quickly identify and address any protocols which do not meet the ALARA (as low as reasonably achievable) principle [1].

It is being argued however, that while reference levels are a guide to good practice, they are neither dose limits nor threshold levels that define competent performance of the operator or the equipment [3]. ICRP has advised however, that DRLs be initiated by local, regional and national bodies to determine their threshold dose. They subsequently made recommendations for both occupational exposures and the public using dose index volume (CTDI volume) and the dose-length product, DLP, the two dosimetric quantities on CT consoles [4].

DLP combines the CTDI ${ }_{\mathrm{vol}}$ and the scan length to quantify the total radiation dose received by the patient during a CT scan hence, permitting a more complete account of the patient dose per examination. Because DLP is directly related to patient risk, it may be used to set reference values for CT examinations [1]. In this work however, dose was quantified by the effective dose which was derived from DLP using an appropriate conversion coefficient [5].

Effective dose which is a risk-weighted measure of radiation to organs in the body associated with an examination is considered a good indicator of radiological risk. Use of effective dose will enable comparisons between different types of radiological exposures since it simplifies the complex distribution of dose to various tissues and organs from a particular exposure into a single-dose parameter [6].

This work sets out to determine the effective dose from our practice with a view to using that dosimetric to recommend diagnostic reference levels for our centre specifically, and as a preliminary guide for the country.

\section{Methods}

A prospective and cross-sectional study involving 30 conscious patients aged 1 to 74 (mean: $41.47 \pm 23.30$ ) years referred for head CT scan between June 23 to July 7, 2014. Ethical approval was got from the research ethics committee of the hospital while patients or their chaperons gave informed, written consent. Thirty-four patients were scanned within the two-week period of the study but only thirty (88\%) met the inclusion criteria. All patients were included except those who were restless as well as those who were not willing to participate in the study. A 32-slice CT scanner that became operational in 2013 was used. Patients were positioned and scanned according to standard protocol for head CT. The total dose-length product were read from the console and recorded at the end of the pre-contrast and post-contrast sequences respectively. The pre-contrast dose was taken into cognizance in the determination of the post-contrast dose. The effective dose was determined by multiplying the dose-length product (DLP) by $0.0023 \mathrm{mSv} \cdot \mathrm{mGy}^{-1} \cdot \mathrm{cm}^{-1}$. SPSS version 17 (SPSS Incorporated, Chicago, Illinois, USA) was used to analyze the data. The $75^{\text {th }}$ percentile of the effective dose was then noted as the threshold for our centre and the mean from this work and two similar works in this environment was recommended as the national threshold. 


\section{Results}

30 patients aged 1 to 74 years with a mean age of $41.47 \pm 23.30$ years participated in the study. Both the precontrast and post-contrast effective doses gave a mean and $75^{\text {th }}$ percentile of $2.56 \pm 0.51 \mathrm{mSv} / 3.11 \mathrm{mSv}$ and 5.27 $\pm 0.97 \mathrm{mSv} / 6.13 \mathrm{mSv}$ respectively. Table 1 summarizes the central tendencies and range. The two other works from Nigeria used a sample size of 40 - 50 patients at a lower $\mathrm{kVp}$ (120) than ours but at a higher mA (215 378). The work with the least $\mathrm{mA}$ (215) derived an effective dose of $2.8 \mathrm{mSv}$ while the one with an $\mathrm{mA}$ of 378 got an effective dose of $3.1 \mathrm{mSv}$ which is same as ours. One of the foreign works which used the maximum $\mathrm{kVp}$ of 140 and a much higher $\mathrm{mA}$ of 580 somehow also got a much-reduced effective dose of $1.8 \mathrm{mSv}$. Although this is inconsistent with current knowledge on dose optimization where increase in $\mathrm{mA}$ increases dose rather than reducing it, with careful optimization such as automatic exposure control (AEC), narrow scan range and a pitch much greater than one, this is realistic. In contrast CT our effective dose of $6.1 \mathrm{mSv}$ is higher than the two other works it was compared with. The effective dose from this study compared with previous works in Nigeria and overseas is shown in Table 2 and Table 3. The results of a test of significance between the three works in our locality shows that there is significant difference between means. This is given in Table 4. The mean effective dose from three separate works in Nigeria is also given (Table 5).

Table 1. Age and dose characteristics of patients.

\begin{tabular}{ccccccc}
\hline $\begin{array}{c}\text { Parameters } \\
\text { sequence }\end{array}$ & $\begin{array}{c}\text { No. of } \\
\text { patients }\end{array}$ & $\begin{array}{c}\text { Mean age } \\
\text { (years) }\end{array}$ & $\begin{array}{c}\text { Minimum effective } \\
\text { dose }(\mathrm{mSv})\end{array}$ & $\begin{array}{c}\text { Maximum } \\
\text { effective dose (mSv) }\end{array}$ & $\begin{array}{c}\text { Mean effective dose } \\
(\mathrm{mSv} \pm \mathrm{SD})\end{array}$ & $\begin{array}{c}75^{\text {th }} \text { percentile of } \\
\text { effective dose }\end{array}$ \\
\hline Pre-contrast & 30 & $41.47 \pm 23.30$ & $1.93 \mathrm{mSv}$ & $3.32 \mathrm{mSv}$ & $2.56 \pm 0.51 \mathrm{mSv}$ & $3.11 \mathrm{mSv}$ \\
Post-contrast & 30 & $4.06 \mathrm{mSv}$ & $6.97 \mathrm{mSv}$ & $5.27 \pm 0.97 \mathrm{mSv}$ & $6.13 \mathrm{mSv}$ \\
\hline
\end{tabular}

Table 2. Comparison of this work with previous works in non-contrast CT.

\begin{tabular}{|c|c|c|c|c|c|}
\hline Authors & Location & Effective dose (mSv) & Sample size & $\mathrm{kVp}$ maximum & $\mathrm{mA}$ maximum \\
\hline Present study & Nigeria & 3.1 & 30 & 140 & 150 \\
\hline Mundi et al. [7] & Nigeria & 3.1 & 40 & 120 & 378 \\
\hline Ogbole et al. [8] & Nigeria & 2.8 & 50 & 120 & 215 \\
\hline Brix et al. [9] & Germany & 2.8 & 9,000 & 122 & 317 \\
\hline Origgi et al. [10] & Italy & 1.8 & 56 & 140 & 580 \\
\hline Osei et al. [6] & Canada & 1.8 & 94 & 138 & 100 \\
\hline
\end{tabular}

Table 3. Comparison of this work with other works in contrast CT.

\begin{tabular}{|c|c|c|c|c|c|}
\hline Authors & Location & Effective dose (mSv) & Sample size & kVp maximum & mA maximum \\
\hline Present study & Nigeria & 6.1 & 30 & 150 & 150 \\
\hline Roberts et al. [11] & Canada & 4.0 & 2 & 80 & 190 \\
\hline Yamauchi-Kawara et al. [12] & Japan & 4.2 & Unknown & Unknown & Unknown \\
\hline
\end{tabular}

Table 4. One-sample t-test amongst works done in Nigeria.

\begin{tabular}{|c|c|c|c|c|c|}
\hline Authors & Location & Effective dose (mSv) & Pre-contrast mean (mSv) & P-value & Remarks \\
\hline Present study (contrast) & Nigeria & 5.3 & 2.56 & $P=0.000$ & Significant \\
\hline Mundi et al. [7] & Nigeria & 3.1 & 2.56 & $P=0.000$ & Significant \\
\hline Ogbole et al. [8] & Nigeria & 2.8 & 2.56 & $P=0.015$ & Significant \\
\hline
\end{tabular}

(CI: $95 \% ; p<0.05$ significant).

Table 5. Preliminary diagnostic reference level for Nigeria in non-contrast brain CT.

\begin{tabular}{ccc}
\hline Authors & Place of research & Effective dose (mSv) \\
\hline Adejoh et al. & Onitsha & 3.1 \\
Mundi et al. [6] & Abuja & 3.1 \\
Ogbole et al. [7] & Ibadan & 2.8 \\
& Mean & 3.0 \\
\hline
\end{tabular}




\section{Discussion}

This work established a threshold effective dose of $3.11 \mathrm{mSv}$ and $6.13 \mathrm{mSv}$ for pre-contrast and post-contrast investigations respectively from our centre and a national mean of $3.0 \mathrm{mSv}$. The quantified effective doses are below threshold limits for occupational exposures but higher than that for the public. The pre-contrast dose rate was also noted to be at the upper limit of ranges found in the review of literature (Table 2).

Two similar works done in our locality to determine dose from CT examinations established values that were lower than ours and with means that were significantly different [7] [8]. Interestingly, the mAs used in their works were higher than ours although their $\mathrm{kVp}$ was lower (Table 2 and Table 3). Data from other regions also show significant reduction in the effective dose thresholds established (Table 2). A closely-similar work for instance, used a maximum of $100 \mathrm{mAs}$ on 94 patients and derived an effective dose of $1.8 \mathrm{mSv}$ for adult head CT examinations [4]. These findings which do not corroborate our work significantly enough, reinforce our thinking that in our centre, there is need to pay conscious attention to dose optimization strategies.

Our CT scanner is a 32-slice machine. As a conscious dose-reduction technique, tube currents above $150 \mathrm{~mA}$ for adults are not exceeded. This work opens our minds to the possibility that with a further reduction in exposure parameters without compromising image quality, a further reduction in effective dose is possible. This thinking is buttressed by the findings of a survey carried out in Germany to investigate dose from single slice and multi-slice CT scanners. The authors established a mean collective effective dose of $2.8 \mathrm{mSv}$ for their population and concluded that considerable dose reduction was observed when single-slice CT was used to examine patients [5]. Since our centre has a multi-slice CT, a reduction in exposure parameters like mAs and kVp may possibly achieve a similar result.

The high dose noted in our work may also not be unconnected with the fact that our patients were not normalized for weight and age. There were several outliers in the ages and weights of the patients which possibly influenced the range of our values and hence shot up our $75^{\text {th }}$ percentile. It was also not possible to tell if some of the works referenced by us used the $75^{\text {th }}$ percentile such as we did. If they used the mean effective dose, then our mean of $2.56 \mathrm{mSv}$ from this work is lower than some. However, since the $75^{\text {th }}$ percentile is recommended as the appropriate cut-off level, we stick with the conclusion that our dose rates appear high.

\section{Conclusion}

The national threshold derived from this work is a preliminary recommendation because data from three centres may not be adequate for inferences involving a whole nation. It is hoped that further works from this environment will build on our foundation until a more-encompassing diagnostic reference level is established. We recommend that this work be replicated in patients normalized for weight and age on a wider scale to track changes in dose levels.

\section{Conflict of Interest}

None.

\section{References}

[1] Foley, S.J., McEntee, M.F. and Rainford, L.A. (2012) Establishment of CT Diagnostic Reference Levels in Ireland. British Journal of Radiology, 85, 1390-1397. http://dx.doi.org/10.1259/bjr/15839549

[2] International Commission on Radiological Protection (1990) Recommendations of the International Commission on Radiological Protection (Report 60). Annals of the ICRP, 21.

[3] Miller, D.L., Kwon, D. and Bonavia, G.H. (2009) Reference Levels for Patient Radiation Doses in Interventional Radiology: Proposed Initial Values for U.S. Practice. Radiology, 253, 753-764. http://dx.doi.org/10.1148/radiol.2533090354

[4] (2007) Recommendations of the International Commission on Radiological Protection. ICRP Publication 103. Annals of ICRP, 37, 1-332.

[5] European Commission (1999) European Guidelines on Quality Criteria for Computed Tomography. Report EUR 16262 EN. Office for Official Publications of the European Commission, Luxembourg, 66-78.

[6] Osei, E.K. and Darko, J.A. (2013) Survey of Organ Equivalent and Effective Doses from Diagnostic Radiology Procedures. ISRN Radiology, 2013, Article ID: 204346. http://dx.doi.org/10.5402/2013/204346 
[7] Abdullahi, M., Shittu, H., Joseph, D., Aribisala, A.-J., Eshiett, E.P., Richard, I. and Kpaku, G. (2015) Diagnostic Reference Level for Adult Brain Computed Tomography Scans: A Case Study of a Tertiary Health Care Center in Nigeria. IOSR Journal of Dental and Medical Sciences, 14, 66-75.

[8] Ogbole, G.I. and Obed, R. (2014) Radiation Doses in Computed Tomography: Need for Optimization and Application of Dose Reference Levels in Nigeria. West African Journal of Radiology, 21, 1-6.

[9] Brix, G., Nagel, H.D., Stamm, G., Veit, R., Lechel, U., Griebel, J. and Galanski, M. (2003) Radiation Exposure in Multi-Slice versus Single-Slice Spiral CT: Results of a Nationwide Survey. European Radiology, 13, 1979-1991. http://dx.doi.org/10.1007/s00330-003-1883-y

[10] Origgi, D., Vigorito, S., Villa, G., Bellomi, M. and Tosi, G. (2006) Survey of Computed Tomography Techniques and Absorbed Dose in Italian Hospitals: A Comparison between Two Methods to Estimate the Dose-Length Product and the Effective Dose and to Verify Fulfillment of the Diagnostic Reference Levels. European Radiology, 16, 227-237. http://dx.doi.org/10.1007/s00330-005-2682-4

[11] Heidi, R.C., Timothy, R.P.L., Ting-Yim, L. and William, D.P. (2002) Dynamic, Contrast-Enhanced CT of Human Brain Tumors: Quantitative Assessment of Blood Volume, Blood Flow, and Microvascular Permeability: Report of Two Cases. American Journal of Neuro-Radiology, 23, 828-832.

[12] Yamauchi-Kawara, C., Fujii, K., Aoyama, T., Yamauchi, M. and Koyama, S. (2010) Radiation Dose Evaluation in Multidetector-Row CT Imaging for Acute Stroke with an Anthropomorphic Phantom. British Journal of Radiology, 83, 1029-1041. http://dx.doi.org/10.1259/bjr/52267127 